\title{
Research Article \\ Study of the Tensile Damage of 321 Stainless Steel for Solar Thermal Power Generation by Acoustic Emission
}

\author{
Lida Liao and Qi Tan (D) \\ School of Energy and Power Engineering, Changsha University of Science and Technology, Changsha 410114, China \\ Correspondence should be addressed to Qi Tan; tq2012@stu.csust.edu.cn
}

Received 8 November 2019; Accepted 27 December 2019; Published 10 January 2020

Guest Editor: Zhangxing He

Copyright (c) 2020 Lida Liao and Qi Tan. This is an open access article distributed under the Creative Commons Attribution License, which permits unrestricted use, distribution, and reproduction in any medium, provided the original work is properly cited.

In this paper, the acoustic emission technique was used to study the signal during the tensile damage of 321 stainless steel for solar thermal power generation. It was found that the peak frequency can effectively distinguish different types of signals during the tensile test. The interference signals generated during the tensile test are effectively resolved by combining the amplitude-peak frequency distribution map and the energy-peak frequency distribution map. The amplitude-time map of the acoustic emission signal is successfully divided into three stages by using peak frequency parameter.

\section{Introduction}

The massive use of fossil fuels has intensified the problem such as energy shortage and environment pollution; therefore, vigorous development of renewable energy is around the corner [1]. Statistics from the International Energy Agency show that electricity production accounts for most of global greenhouse gas emissions, and accordingly, 25,000 GW of low-carbon energy will be required by 2050 to meet the sustainable life on earth $[2,3]$. To mitigate the environmental problems associated with this, it is increasingly important to reduce the use of fossil fuels by developing more cost-effective renewable energy technologies. Among all kinds of renewable energy, solar energy accounts for a large proportion [4]. At present, solar photovoltaic power generation and solar thermal power generation are two main technologies of solar energy utilization. Compared with solar photovoltaic power generation technology, solar thermal power generation technology has the advantages of strong controllability and high flexibility [5], so it is regarded as the preferred equipment for flexible power supply of largescale power grid [6].

Solar thermal power system includes a solar collector, solar receiver, and power conversion device. A solar receiver absorbs concentrated solar radiation through a collector and transmits it to a heat transfer fluid used to transfer hightemperature heat to a power conversion system. The pipelines used in solar thermal power plants to transport thermal fluid require high material stability. 321 stainless steel is a stable and ductile Ti-austenitic stainless steel, and $\mathrm{Ti}$ can effectively mitigate the sensitization effect of materials under high temperature. Therefore, 321 stainless steel is widely used in such important parts as pipelines and heat exchangers of solar thermal power system [7]. In order to ensure the safety and reliability of the structure, it is of great significance to study the tensile damage behavior of 321 stainless steel.

Acoustic emission (AE) is an efficient structural health monitoring technology, which is defined as a phenomenon of rapid energy release and transient elastic wave generation [8, 9]. Acoustic emission technology based on Kaiser's [10] research uses sensors and preamplifiers to detect elastic waves propagating through the material. The $\mathrm{AE}$ monitors through several sensors and preamplifiers to detect elastic waves propagated inside a material, as shown in Figure 1. The signal waves are directly transmitted to the AE system, where these signals would be analyzed and transferred to digital signals. At present, the nondestructive testing methods commonly used for tensile damage include ultrasonic testing, $\mathrm{X}$-ray inspection, computed tomography (CT) detection, infrared thermography techniques, and magnetic memory 


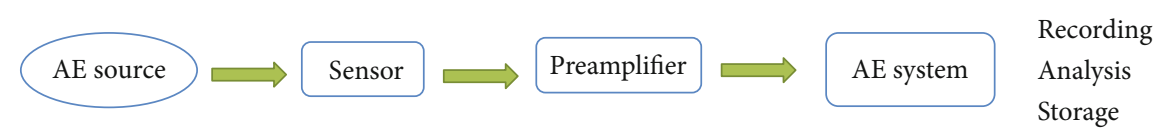

Figure 1: Principles of AE detection. Acoustic emission signal is collected by the sensor, and the preamplifier transmits it to the acoustic emission system.

methods. However, ultrasonic testing requires different probes for different defects, and ultrasonic testing has high requirements on the shape and thickness of the material. $\mathrm{X}$-ray inspection is harmful to the human body, an operator who has special training experience is needed. The disadvantage of CT detection is that it is inconvenient for on-site inspection of large components; furthermore, CT detection is inefficient and costly. The infrared thermography technique has high requirements for the surface heat absorption rate of materials, so it is not suitable for many materials. For magnetic memory testing, the magnetic memory signal is weak, and it is seriously affected by the environmental magnetic field. As a real-time testing method, the acoustic emission technique is more suitable for dynamic evaluation and real-time diagnosis than the abovementioned detection methods. And the acoustic emission technique has characteristics that it is not limited by materials, geometries, and working conditions. Furthermore, acoustic emission detection is a passive detection method; acoustic emission signals come from the detected object, so the detection process will not affect the normal operation of the device. Therefore, acoustic emission technology is widely applied in the detection of deformation and fracture process of various materials. Barile et al. [11] monitored the fatigue process of stainless steel specimens by using AE technology and infrared thermography (IT) technology, and they found that AE technology was more effective than IT technology. A typical AE signal includes many parameters, which are commonly used such as amplitude and count. Amplitude is defined as the peak voltage magnitude of the maximum offset obtained from the signal waveform of the acoustic emission event. Threshold is a voltage level on an electronic comparator such that signals with amplitudes larger than this level will be recognized. Count is defined as the number of times the acoustic emission signal exceeds the threshold. Heiple et al. [12] found that count in the characteristic parameters of the signal can effectively reflect the damage of the material. However, the parameters such as amplitude and count are related to the threshold setting, so analysis by a single parameter is not enough. Acoustic emission energy is the area under the signal detection envelope and is not sensitive to threshold, operating frequency, and propagation characteristics. Roberts and Talebzadeh [13] found that the energy of the signal is less affected by the threshold setting and coupling conditions and the change in the signal energy value can reflect the phase changes inside the material. With the development of acoustic emission technology, many researchers have used acoustic emission technology to study the fatigue process of different materials, such as stainless steel [14], aluminum alloy [15], titanium alloy [16], self-compacting concrete [17], wood material [18], and SIC/SIC composites [19]. In recent years, many researchers have conducted acoustic emission studies on the tensile behavior of various materials and achieved certain results. Sun et al. [20] studied the acoustic emission of tensile damage of high-strength aluminum alloy materials used in the gearbox shell of highspeed train, quantified the evolution of tensile damage of aluminum alloy, and proved the effectiveness of this method. Kumar et al. [21] found that changes in AE parameters could well reflect changes in microstructure of titanium alloy during the tensile process. Sayar et al. [22] investigated damage mechanisms in the open-hole laminated carbon/epoxy composite by using the acoustic emission technology. The results show that different damage stages can be determined by the frequency range of the acoustic emission signal. Njuhovic et al. [23] found that there exists a correlation between the cumulative absolute AE energy and tensile damage of metallised glass fibre-reinforced epoxy composites and different mechanisms of damage can be identified by the peak frequency parameters of the acoustic emission signal. Yao et al. [24] studied the cracking behavior and fracture process of thermal barrier coating under tensile load through acoustic emission technology, and the results showed that acoustic emission signals could reveal the fracture type and failure mechanism. However, at present, there are few researches on tensile damage of 321 stainless steel for solar thermal power generation. Acoustic emission signals contain damage information of material. We can know the internal damage of the material in time by analyzing the parameter of acoustic emission signals. However, the commonly used parameters of acoustic emission signal can easily be affected by various factors, such as parameters of amplitude and count will be affected by the threshold, which cannot accurately characterize the internal damage of the material.

In this paper, we study the tensile damage of 321 stainless steel for solar thermal power generation by using acoustic emission technology. In order to accurately obtain the information of 321 stainless steel for solar thermal power generation during tensile damage, we use the parameter of peak frequency to analyze the tensile damage process of 321 stainless steel. The peak frequency parameters are used to distinguish different types of signals during the tensile test. Peak frequency corresponds to the maximum amplitude of Fourier transform of acoustic emission waveform, which is a parameter sensitive to damage. The peak frequency of acoustic emission signals is not affected by threshold setting, which is more reliable than other parameters. Peak frequency can characterize the types of different acoustic emission sources. The interference signals generated during the tensile test are effectively resolved by combining the amplitude-peak frequency distribution map and the energy-peak frequency distribution map. The amplitude-time map of the acoustic emission signal is divided into three stages by using the peak frequency parameter. The rest of the paper is organized 
TABLE 1: Chemical compositions (wt.\%) of 321 stainless steel.

\begin{tabular}{lcccccccc}
\hline Composition & $\mathrm{C}$ & $\mathrm{Si}$ & $\mathrm{Mn}$ & $\mathrm{P}$ & $\mathrm{S}$ & $\mathrm{Cr}$ & $\mathrm{Ni}$ & $\mathrm{Ti}$ \\
\hline Wt.\% & 0.08 & 1.00 & 2.00 & 0.035 & 0.03 & $17-19$ & $9-12$ & $5^{*} \mathrm{C} \%$ \\
\hline
\end{tabular}
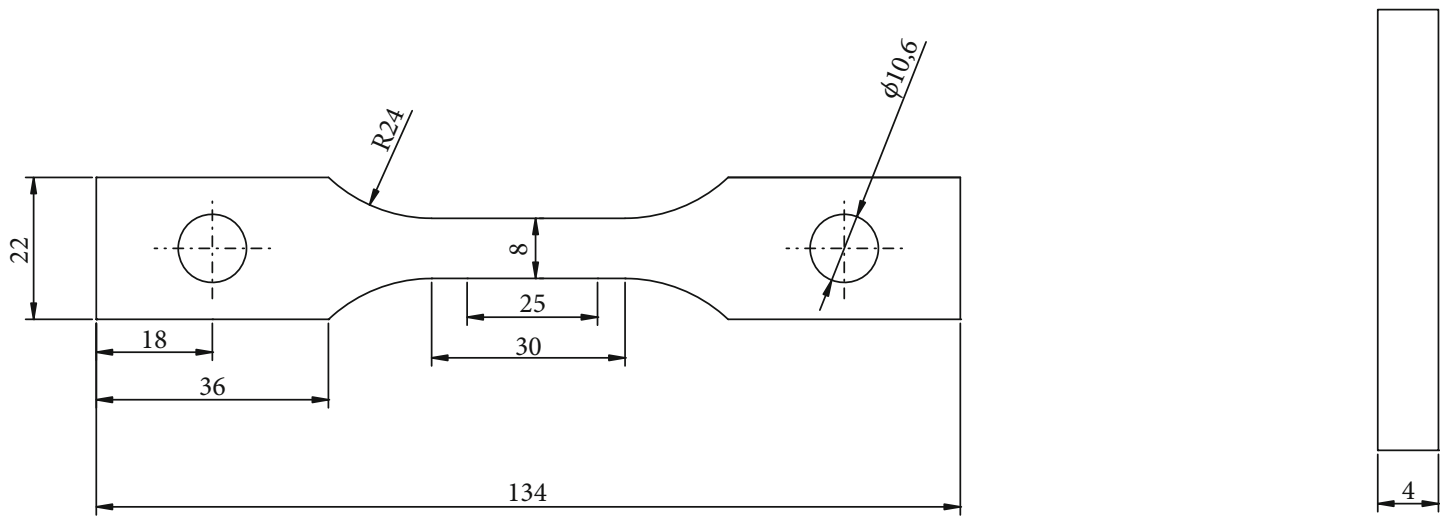

FIgure 2: Geometry of tensile specimen. The specimen was machined to a thickness of $4 \mathrm{~mm}$

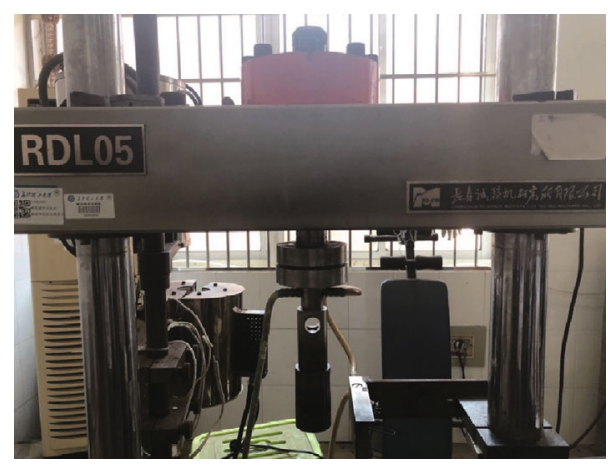

Figure 3: RDL05 testing machine of the tensile experiment. The maximum load of the machine is $50 \mathrm{kN}$.

as follows: in the second part, the materials used in the experiment are introduced, the third part is the analysis and discussion of the acoustic emission signals obtained from the tensile test, and the fourth part summarizes the results obtained.

\section{Materials and Methods}

2.1. Materials and Specimen. The material used in this study is 321 stainless steel used for solar thermal power generation, which is a Ti-containing austenite stainless steel. The 321 stainless steel has stable and ductile characteristics. Its chemical composition is shown in Table 1.

The specimen was machined from the stainless steel plates to a thickness of $4 \mathrm{~mm}$ in accordance with GB/T228.1-2010 standard. The 321 stainless steel plate is cut in the rolling direction, with the section size of $4 \mathrm{~mm} *$ $8 \mathrm{~mm}$. Figure 2 shows the geometry of the sample.

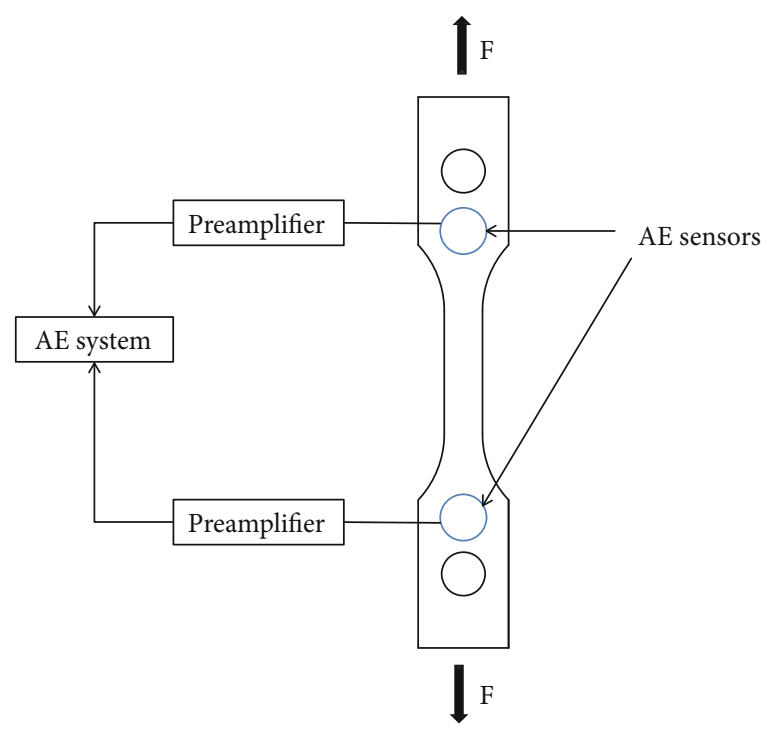

Figure 4: Schematic of the experimental process. Two acoustic emission sensors are fixed on the surface of the specimen to collect signals.

2.2. Tensile Tests. Tensile tests were carried out according to GB/T228.1-2010 standard on a RDL05 testing machine at ambient temperature. The maximum load of the machine is $50 \mathrm{kN}$. Specimens were tested with a loading rate controlled at $0.3 \mathrm{~mm} / \mathrm{min}$. The machine of the tensile experiment is shown in Figure 3.

2.3. AE Monitoring Setup. The AE signals generated from the tensile tests were recorded and analyzed by PCI-2 AEwin system, supplied by Physical Acoustic Corporation (PAC). Schematic of the experimental process is shown in Figure 4. Acoustic emission signals generated by 321 stainless steel 


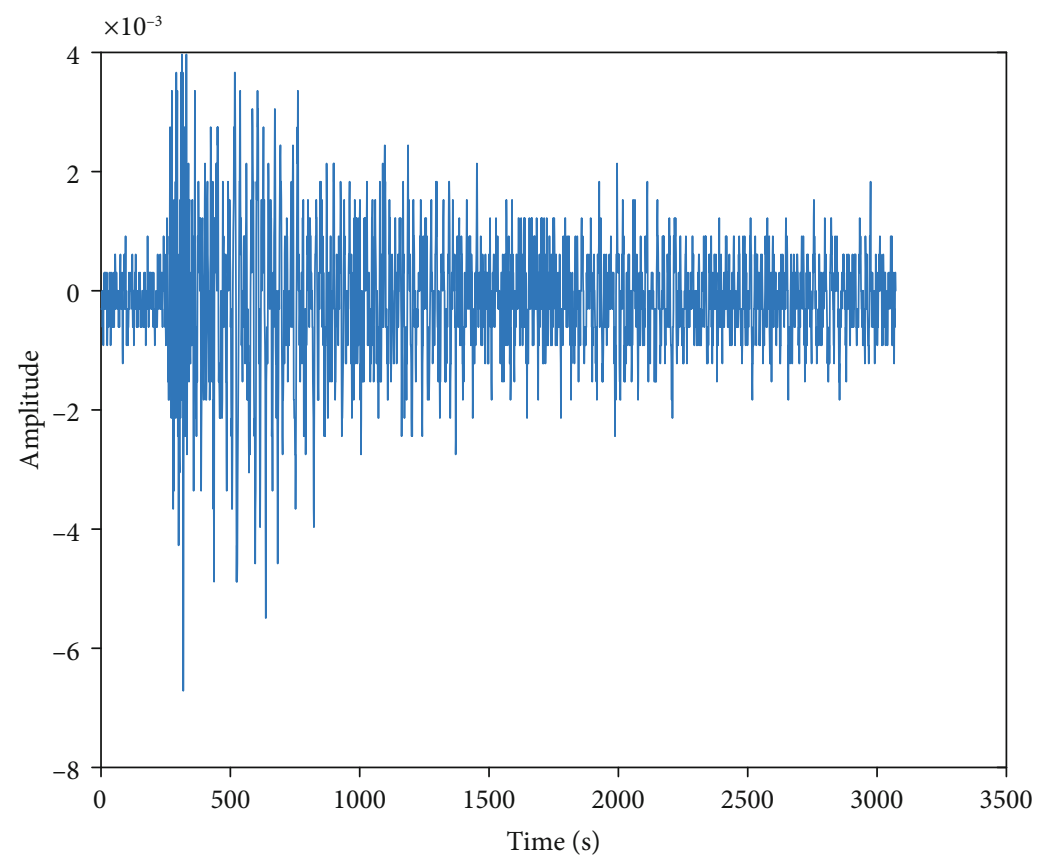

FIGURE 5: Time-domain graphic of the original signal. Time-domain figure obtained through processing the signals collected by the acoustic emission equipment.

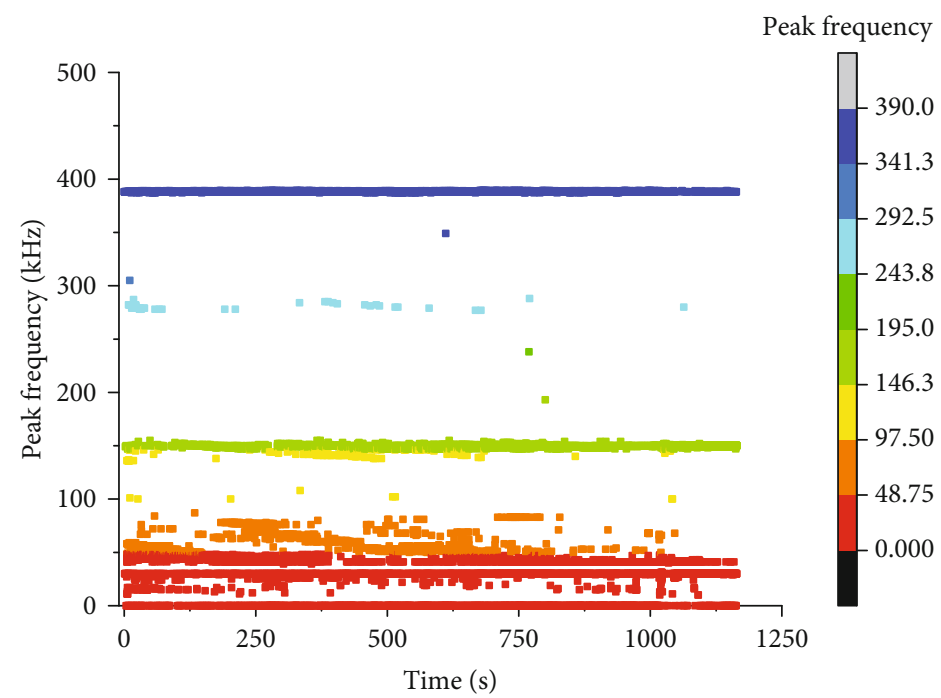

FIGURE 6: Distribution of peak frequency during tensile test. There are five types of peak frequency signals during the tensile test, which are distributed in five ranges: $0-48 \mathrm{kHz}, 50-97 \mathrm{kHz}$, near $149 \mathrm{kHz}$, around $284 \mathrm{kHz}$, and near $388 \mathrm{kHz}$.

during tensile damage are collected by two acoustic emission sensors (R15a) and then transmitted to the acoustic emission system through two $2 / 4 / 6$ preamplifiers with a gain of $40 \mathrm{~dB}$. Figure 5 is the time-domain graphic of the original signal. Acoustic emission sensors installed on the specimen surface, using vacuum grease as the coupling agent. The peak determination time (PDT), hit determination time (HDT), and hit observation time (HLT) were set to 300, 600, and 1000, respectively. The collection of these time-driven parameters was performed using standard lead core fracture. Based on these preparation, we set the threshold value at $25 \mathrm{~dB}$ to eliminate the external noise. An acoustic emission test was carried out until the final fracture appeared.

\section{Results and Discussion}

3.1. Analysis of the Peak Frequency-Time Map of Acoustic Emission Signals. An acoustic emission device was used to monitor the tensile damage process of 321 stainless steel, and the acoustic emission signals were collected and recorded 


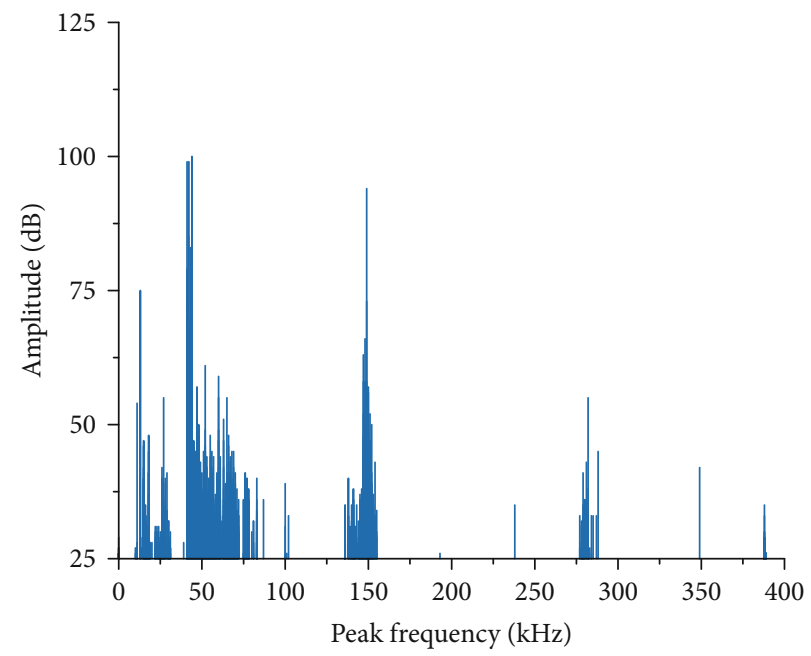

Figure 7: Distribution of amplitude with peak frequency. There are three concentrated sub-ranges in the range $0-48 \mathrm{kHz}$.

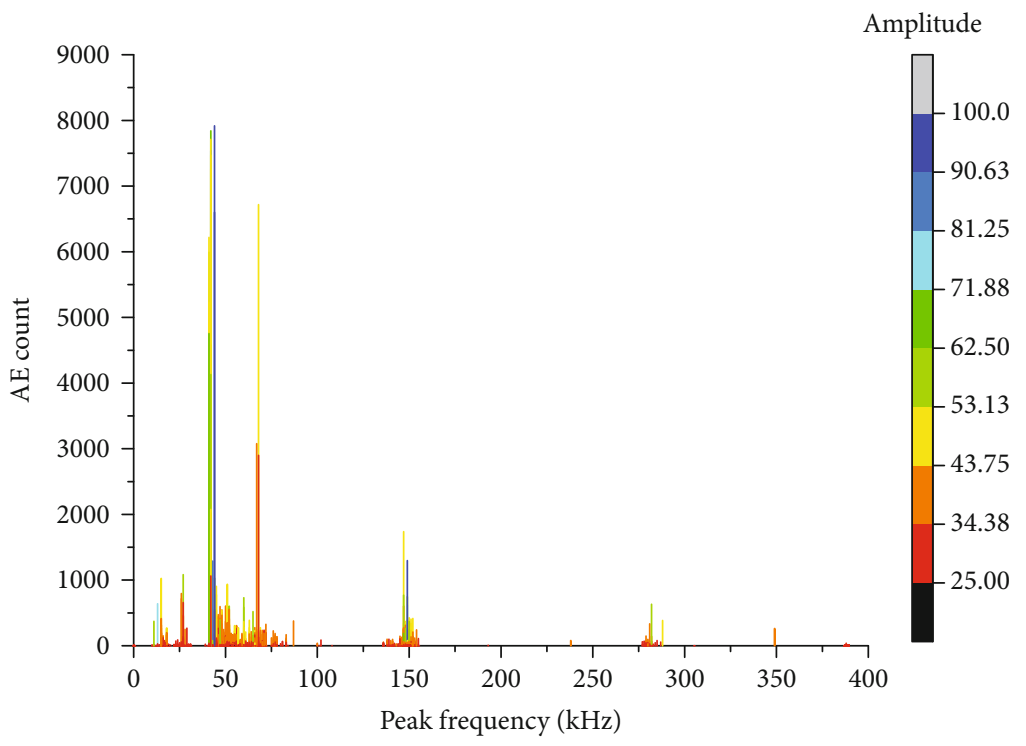

FIGURE 8: Distribution of AE count with peak frequency. The acoustic emission count of range near $388 \mathrm{kHz}$ was very low.

by acoustic emission system. We obtained a distribution plot of the peak frequency during the tensile damage process by extracting the peak frequency parameters of the collected acoustic emission signals and correlating the peak frequency parameters with time. Figure 6 shows a typical plot of peak frequency vs. time for specimen during the tensile test. It can be clearly found that there are five different ranges of peak frequency signals throughout the tensile test. In range 1 , about $0-48 \mathrm{kHz}$, the distribution of the peak frequency parameter is scattered. In range $2,50-97 \mathrm{kHz}$, the distribution of peak frequency parameters concentrated relative to range 1. In range 3, near $149 \mathrm{kHz}$, its peak frequency distribution is more concentrated. In range 4 , around $284 \mathrm{kHz}$, the peak frequency signal of this range appears intermittently throughout the tensile test, but the frequency is concentrated. In range 5 , near $388 \mathrm{kHz}$, the peak frequency is very concen- trated. It can be seen that the peak frequency parameters can distinguish different types of signals well.

3.2. Analysis of the Peak Frequency Distribution. Due to amplitude parameters and count parameters can intuitively show the characteristics of the signal, in order to know the difference in parameter of amplitude and count between types of peak frequency signals, we obtained a plot about the distribution of peak frequency with these two parameters during the tensile test by correlating amplitude parameters and counting parameters with peak frequency parameters, as shown in Figures 7 and 8. It is apparent that there are three concentrated subranges in the range $1(0-48 \mathrm{kHz})$, respectively, around $13 \mathrm{kHz}$, around $27 \mathrm{kHz}$, and around $44 \mathrm{kHz}$. Obviously, the highest value of amplitude is around $44 \mathrm{kHz}$, reaching $100 \mathrm{~dB}$, and has a very high value of count. 


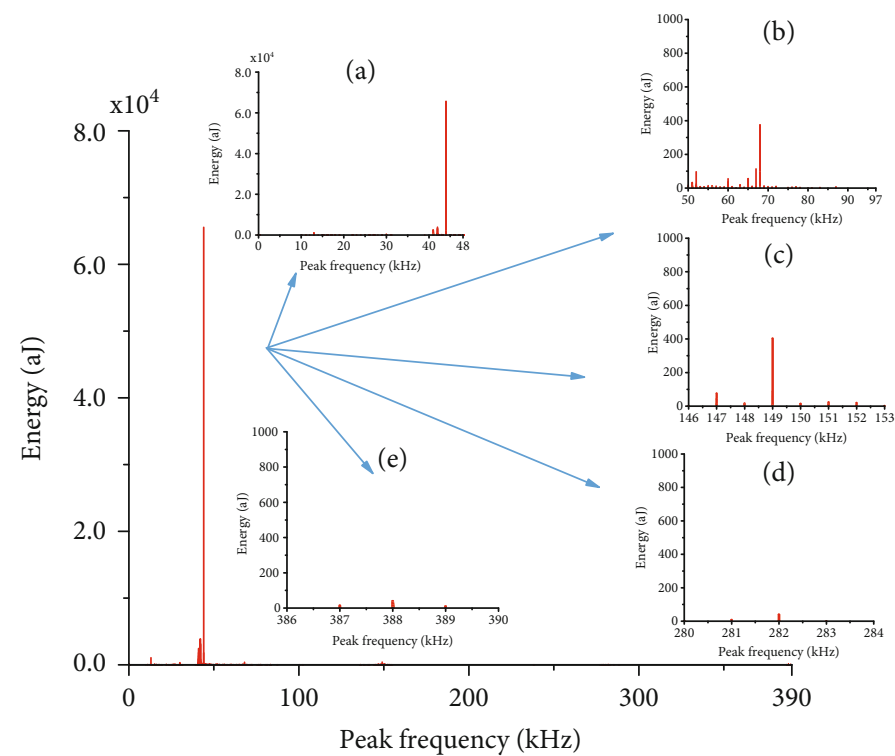

FIGURE 9: Distribution of AE energy with peak frequency: (a) range 0-48 kHz, (b) range 50-97 kHz, (c) near $149 \mathrm{kHz}$, (d) around $284 \mathrm{kHz}$, and (e) near $388 \mathrm{kHz}$.

However, because the amplitude and count parameters are affected by the threshold setting, analysis based on these two parameters alone will cause inaccurate results. Therefore, peak frequency signals in different ranges are analyzed by combining with energy parameter, which is not affected by the threshold setting. Figure 9 shows an energy distribution plot of the peak frequency signal appearing during tensile damage, which is obtained by corresponding acoustic emission signals of different peak frequencies with the released energy. Furthermore, the energy of value distribution figure in five different peak frequency ranges was obtained. In range $1(0-48 \mathrm{kHz})$, the energy released is the highest in the whole test. The signal of range 2 (peak frequency $50-97 \mathrm{kHz}$ ) exhibits low amplitude and high count characteristics, wherein the signal with a peak frequency at $68 \mathrm{kHz}$ releases the acoustic emission count only after $44 \mathrm{kHz}$, and the energy is low. The amplitude of the signal in range 3 (the peak frequency is around $149 \mathrm{kHz}$ ) is on the rise, and the amplitude is concentrated in the range below $50 \mathrm{~dB}$, and the energy is low. The range of sound emission signals in range 4 (the peak frequency is around $284 \mathrm{kHz}$ ) is relatively low, and the energy is extremely low compared to other types of peak frequencies. However, when the peak frequency is in range 4 (near $388 \mathrm{kHz}$ ), the amplitude is extremely low, the acoustic emission count is very small, and the energy is extremely low. Therefore, signals with peak frequencies around $284 \mathrm{kHz}$ and $388 \mathrm{kHz}$ are classified as interference signals.

In range 1 , the amplitude of the signal near $13 \mathrm{kHz}$ is concentrated in the range of more than $50 \mathrm{~dB}$, and the amplitude of the signal near the peak of $27 \mathrm{kHz}$ is mostly less than $50 \mathrm{~dB}$. However, it is impossible to judge from the amplitude distribution that which peak frequency is generated by the material itself, and therefore, the distribution of the energy of the two is found. It can be seen from Figures 10 and 11 that

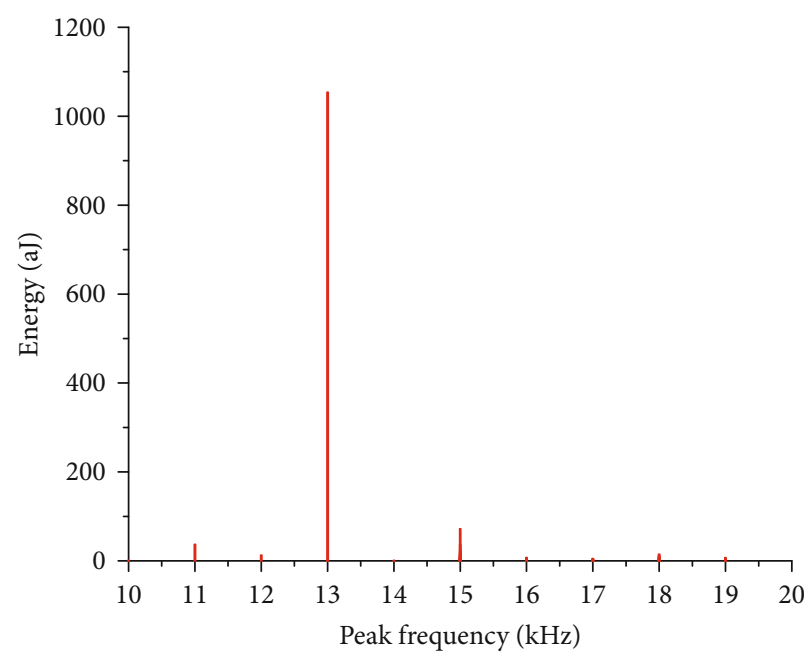

Figure 10: Distribution of AE energy with peak frequency (around $13 \mathrm{kHz}$ ). The range near $13 \mathrm{kHz}$ is where the high acoustic emission energy is released.

the energy of the peak frequency near $27 \mathrm{kHz}$ is extremely low, close to zero, and the energy at $13 \mathrm{kHz}$ is much higher. Therefore, it can be judged that the peak frequency is an interference signal at $27 \mathrm{kHz}$. Finally, four peak frequency ranges capable of expressing the tensile damage signal of the material were obtained: $13 \mathrm{kHz}, 44 \mathrm{kHz}, 68 \mathrm{kHz}$, and $149 \mathrm{kHz}$.

It can be found that the signal source can not be accurately judged by the amplitude and peak frequency distribution map, and a large error will occur. The energy and peak frequency distribution map can find the interference signal, but it has no obvious distribution characteristics of the former. Therefore, by combining the amplitude-peak frequency 


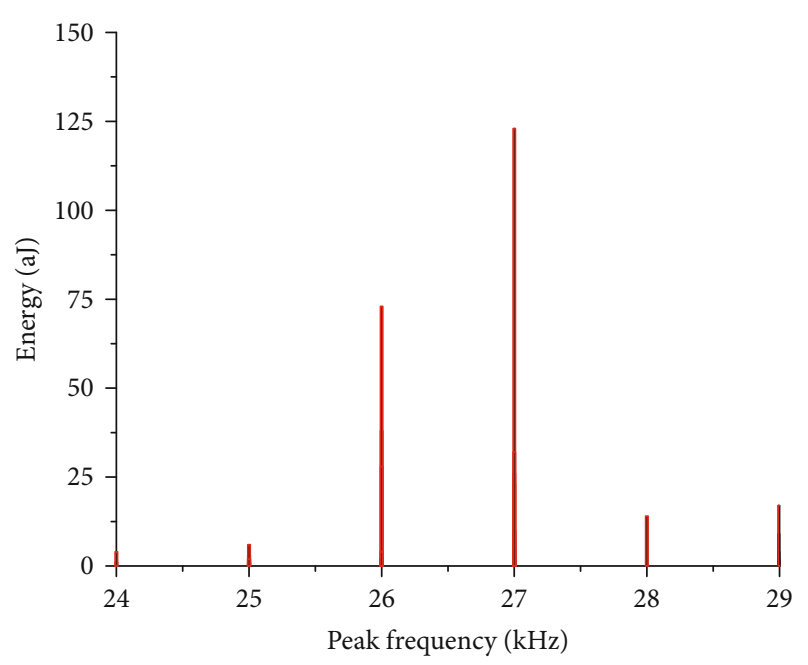

Figure 11: Distribution of AE energy with peak frequency (around $27 \mathrm{kHz}$ ). The range near $27 \mathrm{kHz}$ of acoustic emission energy released in a very low level.

distribution map and the energy-peak frequency distribution map, it is possible to effectively distinguish the interference signal from the material self-damage signal.

3.3. Analysis of Amplitude History of Different Types of Peak Frequency Signals. Figure 12 shows the trend of amplitude with time during tensile test, which is divided into three stages according to the peak frequency. The peak frequency appears in the initial set of stages (stage1) and the stage of the break (stage3) in the signal set of range 1, indicating that the signals produced by the two stages are of the same type. In phase 2, signals with peak frequencies in the range of $68 \mathrm{kHz}$ and $149 \mathrm{kHz}$ are simultaneously present, indicating that two different types of acoustic emission signals are generated at this stage. The damage mechanism at each stage of the material stretching process is different, so different types of signals represent different damage mechanisms. The peak frequency can well classify the amplitude history map of the acoustic emission signal into different stages and can understand the type of material damage.

\section{Conclusions}

In this paper, we used acoustic emission technology to study the tensile damage signal of 321 stainless steel for solar thermal power generation. 321 stainless steel is a ductile Ti-austenitic stainless steel, which is widely used in pipelines and heat exchangers of solar thermal power system. However, there is little research on tensile damage of 321 stainless steel by using a more convenient and efficient method. We detect tensile damage of 321 stainless steel for solar thermal power generation by using an acoustic emission technique. As a real-time testing method, the advantage of the acoustic emission technique is that it is not limited by the type of material and geometry. Compared with current detection methods for material tensile damage, we can detect 321 stainless steel for solar energy more efficiently and conveniently by using acoustic emission technology. Through the analysis of the amplitude and frequency history of the acoustic emission signal, the peak frequency distribution map, and the amplitude history of different types of peak frequency signals, the following conclusions can be drawn:

(1) The peak frequency can distinguish different types of signals better than parameters of amplitude and count during the tensile damage test. It can effectively distinguish the interference signal from the material damage signal by combining the peak frequency and energy parameters of the acoustic emission signal during the tensile damage of 321 stainless steel

(2) From the results, we found that the peak frequency of the 321 stainless steel tensile damage process is mainly concentrated in the following five ranges: $0-48 \mathrm{kHz}, \quad 50-97 \mathrm{kHz}$, around $149 \mathrm{kHz}$, around $284 \mathrm{kHz}$, and around $388 \mathrm{kHz}$. And there are three subranges in the range $0-48 \mathrm{kHz}$ : around $13 \mathrm{kHz}$, around $27 \mathrm{kHz}$, and around $44 \mathrm{kHz}$. According to the distribution of $\mathrm{AE}$ energy with peak frequency, we found that the range of peak frequency near $27 \mathrm{kHz}$ is an interference signal with a very low level of energy. Combining the values of the count and energy parameters, we found that the count and energy values of the signal with peak frequency range around $284 \mathrm{kHz}$ and $388 \mathrm{kHz}$ are extremely low, which also are interference signals. Finally, we obtained four kinds of peak frequency ranges that can represent the tensile damage signal of the material: around $13 \mathrm{kHz}, 44 \mathrm{kHz}, 68 \mathrm{kHz}$, and $149 \mathrm{kHz}$

(3) The tensile damage process is divided into three stages by combining the trend of amplitude and peak frequency over time. The peak frequencies of the signals appearing in stages 1 and 3 are concentrated in the range of $0-48 \mathrm{kHz}$, which are mainly composed of signals with peak frequencies around $13 \mathrm{kHz}$ and $44 \mathrm{kHz}$. The peak frequency of the signal appearing in stage 2 is in the range of around $68 \mathrm{kHz}$ and around $149 \mathrm{kHz}$. The first stage is the initial stage of tensile damage of 321 stainless steel, and the third stage is the fracture stage. The appearance of signals with peak frequency ranges around $13 \mathrm{kHz}$ and $44 \mathrm{kHz}$ can serve as a reminder that the 321 stainless steel is entering the fracture stage, which allows us to understand the damage of the equipment in advance so that safety measures can be taken before the accident

At present, we have known that there are five types of peak frequency during the tensile damage process of 321 stainless steel, which are related to the tensile damage source mechanism of 321 stainless steel. Therefore, further work is to quantify tensile damage of 321 stainless steel by establishing relationship between the peak frequency of acoustic emission signals and the tensile damage mechanism. In addition, 


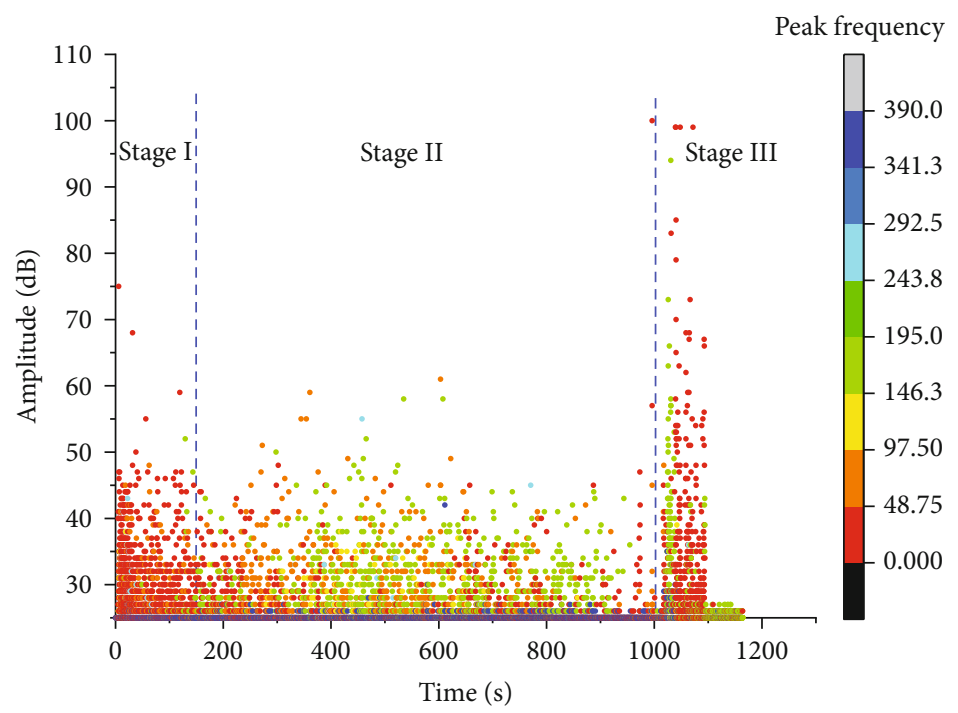

FIGURE 12: Trend of amplitude with time. The whole test was divided into three stages by the peak frequency.

this testing method has not been applied to actual solar thermal storage system and associated pipelines. There is still work to be done in the application of acoustic emission technique in actual solar thermal storage system.

\section{Data Availability}

The data used to support the findings of this study are available from the corresponding author upon request.

\section{Conflicts of Interest}

The authors declare that they have no conflicts of interest.

\section{Acknowledgments}

Funding that permitted this research was granted by the Key Laboratory of Renewable Energy Electric-Technology of Hunan Province (Grant No. 2015ZNDL007), Key Laboratory of Efficient \& Clean Energy Utilization at Changsha University of Science and Technology (Grant No. 2013NGQ009), "Practice Innovation and Entrepreneurship Enhancement Program" for Changsha University of Science and Technology (Grant No. SJCX201957), "International Collaborative Research Underpin Double-First-Class University Development" (Grant No. 2019IC17), and the Education Department of Hunan Province (Grant No. 19B021). The authors would like to acknowledge the Education Department of Hunan Province and Changsha University of Science \& Technology for the funding opportunities and financial support.

\section{References}

[1] O. Behar, A. Khellaf, and K. Mohammedi, "A review of studies on central receiver solar thermal power plants," Renewable \& Sustainable Energy Reviews, vol. 23, pp. 12-39, 2013.

[2] "The future of solar energy- an interdisciplinary MIT study," Energy Initiative Massachusetts Institute of Technology, 2015.
[3] $\mathrm{CO}_{2}$ ermissions from fuel combustion highlights, International Energy Agency, Paris, 2015.

[4] A. F. Regin, S. C. Solanki, and J. S. Saini, "Heat transfer characteristics of thermal energy storage system using PCM capsules: a review," Renewable \& Sustainable Energy Reviews, vol. 12, no. 9, pp. 2438-2458, 2008.

[5] B. Xu, P. W. Li, and C. Chan, "Application of phase change materials for thermal energy storage in concentrated solar thermal power plants: a review to recent developments," Applied Energy, vol. 160, pp. 286-307, 2015.

[6] J. Sun, Q. B. Liu, and H. Hong, "Numerical study of parabolictrough direct steam generation loop in recirculation mode: characteristics, performance and general operation strategy," Energy Conversion and Management, vol. 96, pp. 287-302, 2015.

[7] M. Lang, J. Johnson, J. Schreiber et al., "Cyclic deformation behaviour of AISI 321 austenitic steel and its characterization by means of HTC-SQUID," Nuclear Engineering and Design, vol. 198, no. 1-2, pp. 185-191, 2000.

[8] ASTM E976-10, Standard Guide for Determining the Reproducibility of Acoustic Emission Sensor Response, ASTM International, West Conshohocken, PA, USA, 2010.

[9] ASTM E1316-14, Standard Terminology for Nondestructive Examinations, ASTM International, West Conshohocken, PA, USA, 2014.

[10] W. Kaiser, "Recent progress in stimulated Raman scattering," Ieee Journal of Quantum Electronics, vol. 4, no. 5, p. 381, 1968.

[11] C. Barile, C. Casavola, G. Pappalettera, and C. Pappalettere, "Analysis of crack propagation in stainless steel by comparing acoustic emissions and infrared thermography data," Engineering Failure Analysis, vol. 69, pp. 35-42, 2016.

[12] C. R. Heiple, S. H. Carpenter, and M. J. Carr, “Acoustic emission from dislocation motion in precipitation-strengthened alloys," Metal Science, vol. 15, no. 11-12, pp. 587-598, 1981.

[13] T. M. Roberts and M. Talebzadeh, "Acoustic emission monitoring of fatigue crack propagation," Journal of Constructional Steel Research, vol. 59, no. 6, pp. 695-712, 2003.

[14] M. Y. Chai, Z. X. Zhang, Q. Duan, and Y. Song, "Assessment of fatigue crack growth in $316 \mathrm{LN}$ stainless steel based on acoustic 
emission entropy," International Journal of Fatigue, vol. 109, pp. 145-156, 2018.

[15] M. Y. Bhuiyan and V. Giurgiutiu, "The signatures of acoustic emission waveforms from fatigue crack advancing in thin metallic plates," Smart Materials and Structures, vol. 27, no. 1, p. 015019, 2018.

[16] M. Strantza, D. Van Hemelrijck, P. Guillaume, and D. G. Aggelis, "Acoustic emission monitoring of crack propagation in additively manufactured and conventional titanium components," Mechanics Research Communications, vol. 84, pp. 8-13, 2017.

[17] C. Chen, X. D. Chen, and S. S. Guo, "Experimental study on acoustic emission characteristic of fatigue crack growth of self-compacting concrete," Structural Control \& Health Monitoring, vol. 26, no. 4, p. e2332, 2019.

[18] M. Diakhate, N. Angellier, R. M. Pitti, and F. Dubois, "On the crack tip propagation monitoring within wood material: cluster analysis of acoustic emission data compared with numerical modelling," Construction and Building Materials, vol. 156, pp. 911-920, 2017.

[19] G. N. Morscher and R. Maxwell, "Monitoring tensile fatigue crack growth and fiber failure around a notch in laminate SIC/SIC composites utilizing acoustic emission, electrical resistance, and digital image correlation," Journal of the European Ceramic Society, vol. 39, no. 2-3, pp. 229-239, 2019.

[20] C. Sun, W. D. Zhang, Y. B. Ai, and H. Que, "Study of the tensile damage of high-strength aluminum alloy by acoustic emission,” Metals, vol. 5, no. 4, pp. 2186-2199, 2015.

[21] J. Kumar, S. Punnose, C. K. Mukhopadhyay, T. Jayakumar, and V. Kumar, "Acoustic emission during tensile deformation of smooth and notched specimens of near alpha titanium alloy," Research in Nondestructive Evaluation, vol. 23, no. 1, pp. 17-31, 2012.

[22] H. Sayar, M. Azadi, A. Ghasemi-Ghalebahman, and S. M. Jafari, "Clustering effect on damage mechanisms in openhole laminated carbon/epoxy composite under constant tensile loading rate, using acoustic emission," Composite Structures, vol. 204, pp. 1-11, 2018.

[23] E. Njuhovic, M. Brau, F. Wolff-Fabris, K. Starzynski, and V. Altstädt, "Identification of failure mechanisms of metallised glass fibre reinforced composites under tensile loading using acoustic emission analysis," Composites Part B: Engineering, vol. 81, pp. 1-13, 2015.

[24] W. B. Yao, C. Y. Dai, W. G. Mao, C. Lu, L. Yang, and Y. C. Zhou, "Acoustic emission analysis on tensile failure of air plasma-sprayed thermal barrier coatings," Surface \& Coatings Technology, vol. 206, no. 18, pp. 3803-3807, 2012. 

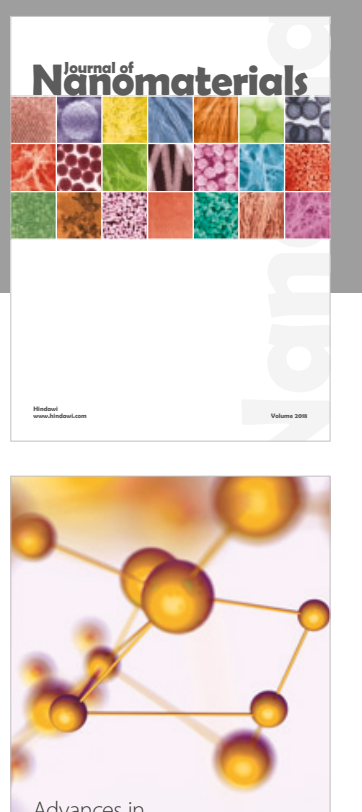

Physical Chemistry
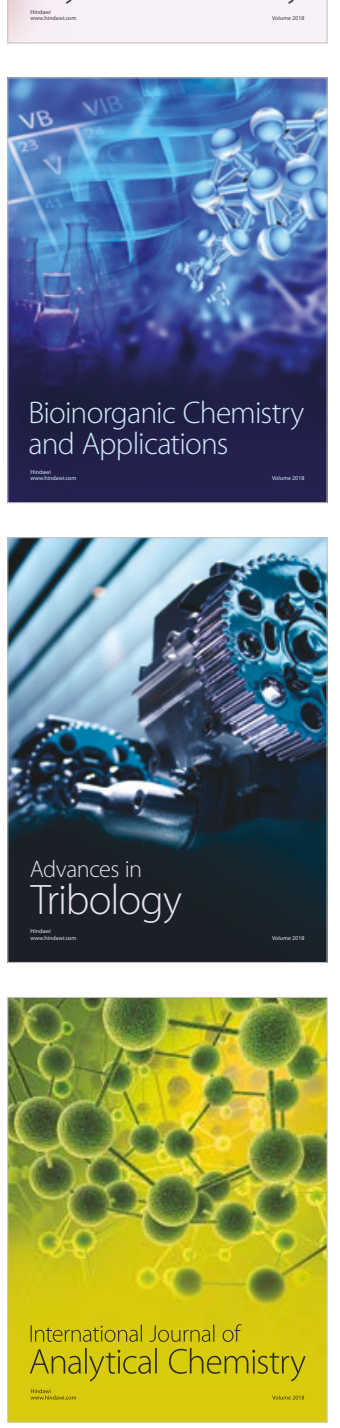

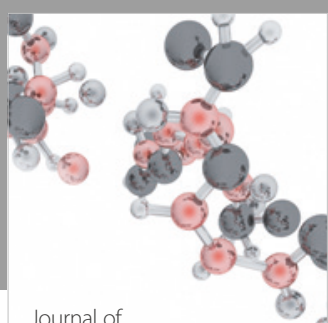

Analytical Methods

in Chemistry

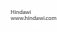

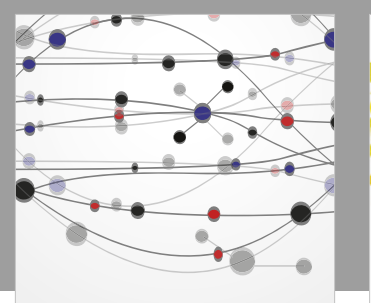

The Scientific World Journal

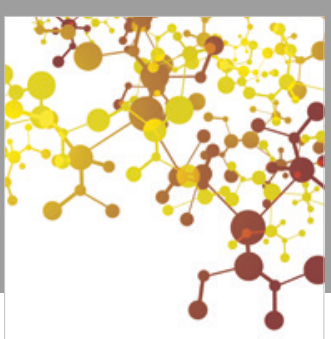

Journal of

Applied Chemistry
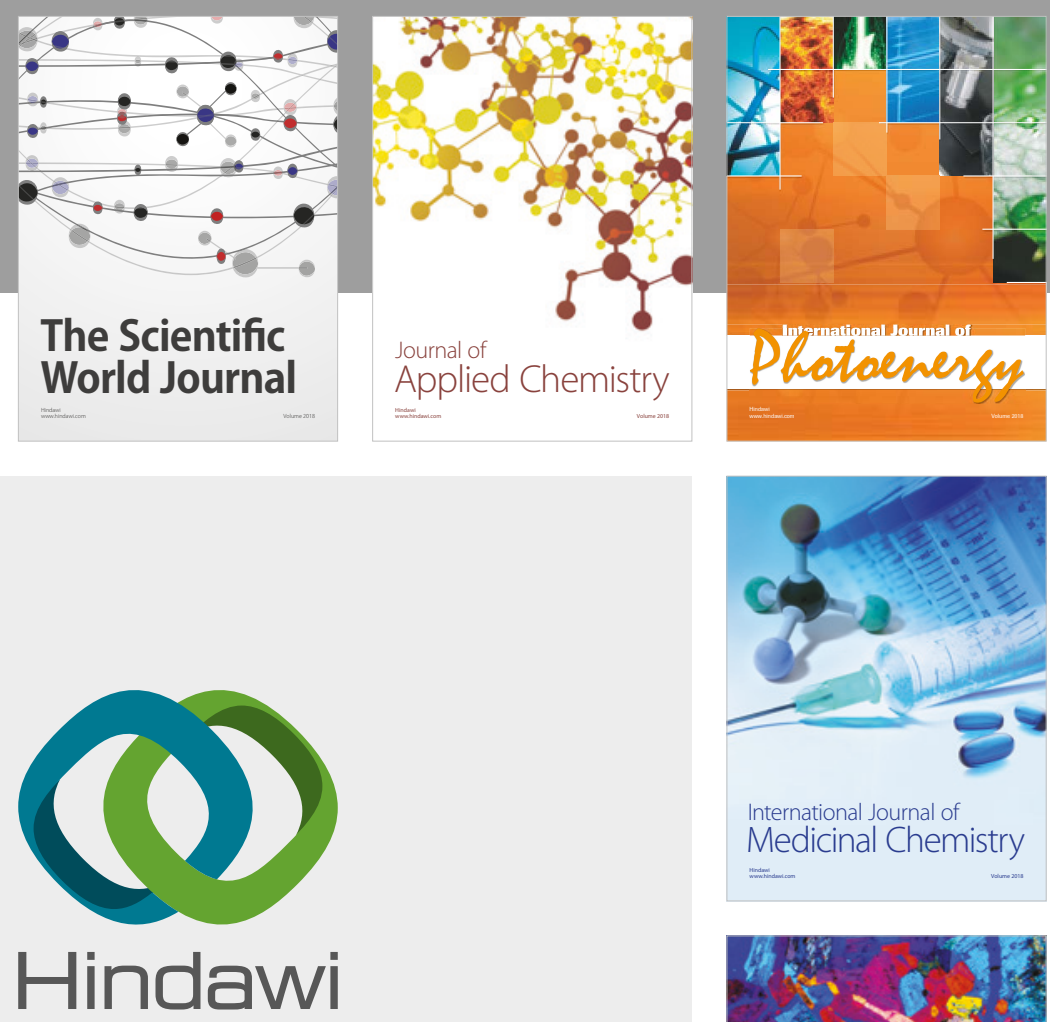

Submit your manuscripts at

www.hindawi.com
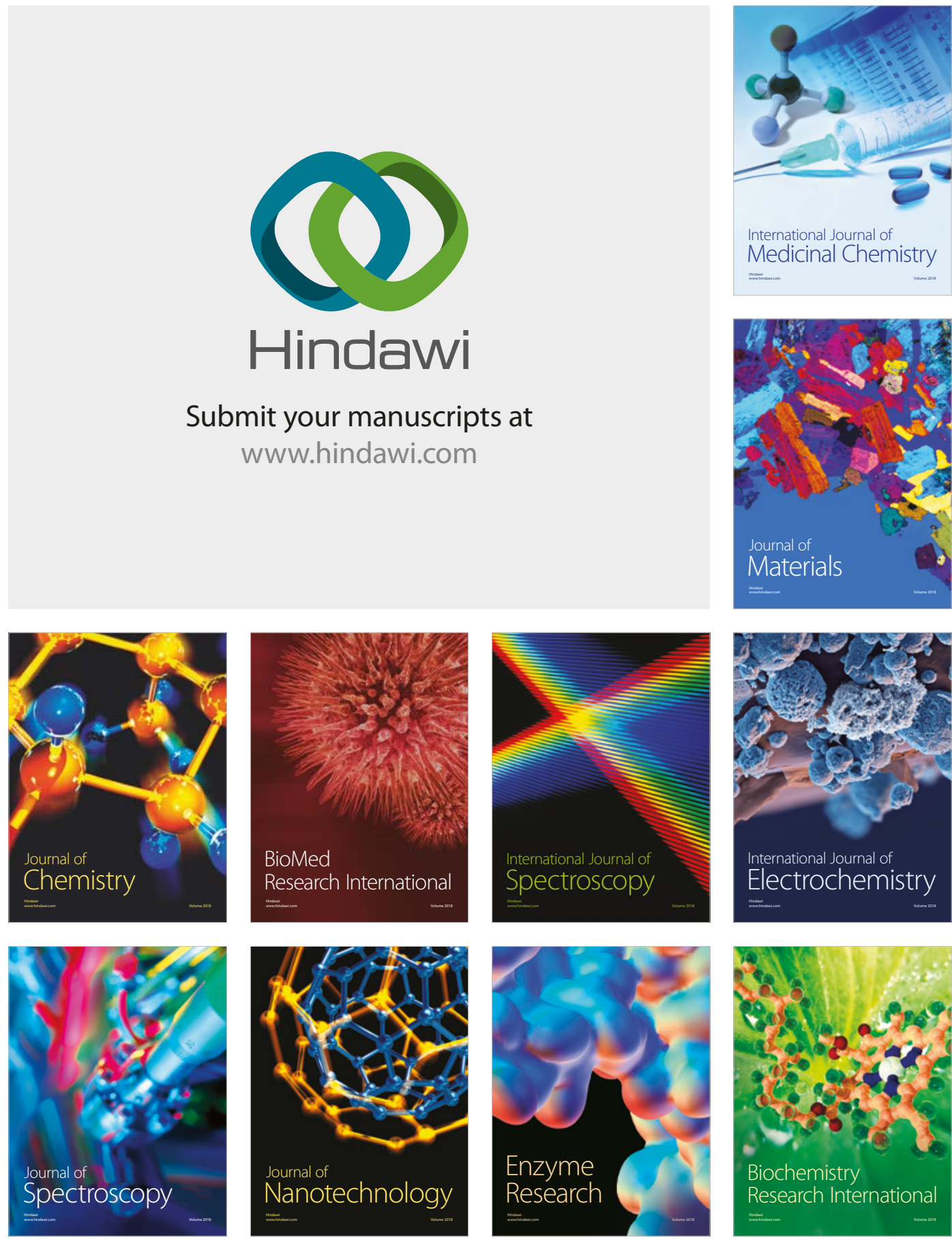
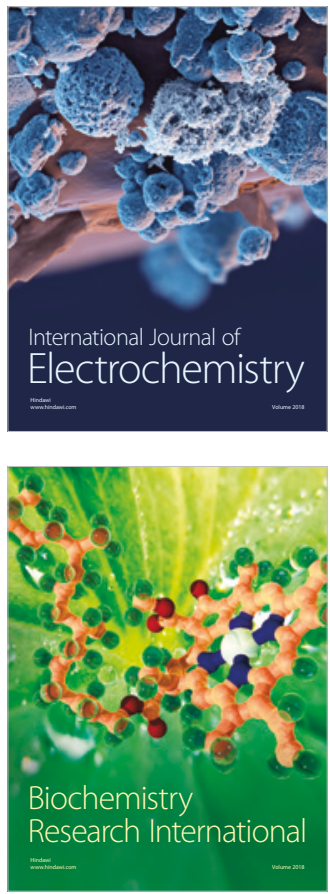